\title{
Management of Recurrent Acute Thrombotic Occlusion of a Giant Coronary Artery Aneurysm Presenting with Recurrent Inferior ST Segment Elevation Myocardial Infarction
}

\author{
Liew Boon Wah Matthew*, Lee Shao Guang Sheldon and Lim Yaozong Benji \\ Department of Cardiology, Changi General Hospital, Singapore \\ *Corresponding author: Liew Boon Wah Matthew, Department of Cardiology, Changi General Hospital, \\ 2 Simei Street 3, 529889, Singapore
}

\begin{abstract}
Case Summary
Giant coronary artery aneurysm is an uncommon finding during coronary angiogram. There is limited data or consensus on the management of patients with giant coronary artery aneurysm in the setting of acute coronary syndrome.

We present a unique case of a recurrent thrombotic occlusion of the right coronary artery presenting as recurrent inferior wall ST segment elevation myocardial infarction (STEMI) requiring percutaneous coronary intervention. He had failed trial of novel anticoagulant with anti-platelet therapy and was switched to triple therapy of a vitamin $\mathrm{K}$ antagonist and dual anti-platelet regime after the second percutaneous coronary intervention. There is limited consensus on the optimal antithrombotic regime for patients with giant coronary artery aneurysm presenting with recurrent thrombosis. Further studies looking into optimal combination therapy are needed to fill this current gap in knowledge.
\end{abstract}

\section{Keywords}

Thrombosis, Giant coronary artery aneurysm, Myocardial infarction, STEMI

\section{Case Report}

We present a unique case of a 62-years-old gentleman who was admitted for recurrent acute inferior ST-segment myocardial infarction (STEMI) due to recurrent acute thrombosis of a giant right coronary artery aneurysm. Mr ABH had no known prior medical illnesses and he was a non-smoker. He presented to the Emergency Department with complaints of severe chest pressure. A 12 lead electrocardiogram (ECG) showed ST segment elevation in the inferior leads II, III and aVF (Figure 1).
He was loaded with oral Aspirin $300 \mathrm{mg}$, Ticagrelor $180 \mathrm{mg}$ and underwent an emergency percutaneous coronary intervention ( $\mathrm{PCl}$ ). A diagnostic coronary angiogram performed via the right radial artery approach showed huge aneurysmal coronary arteries with slow flow in the left coronary system as well as the right coronary artery (RCA) (See Figure 2a, Figure 2b, Figure 3a and Figure $3 b$ ). There was an acute thrombotic occlusion of the mid segment of a giant RCA aneurysm.

We proceeded with $\mathrm{PCl}$ to the culprit lesion at the mid segment of the RCA. A trial of manual aspiration thrombectomy using a Thrombuster ${ }^{\mathrm{TM}}$ (Kaneka Medix Corp) was attempted to no avail. Rheolytic thrombectomy was then performed using Angiojet ${ }^{\mathrm{TM}}$ (Boston Scientific) and TIMI 3 flow was achieved at the end of the procedure. However, there was a visible residual thrombus noted at the mid segment of the RCA. There was no coronary stent deployed as we did not have any available stents to match the size of the coronary artery aneurysm. There was resolution of chest pain symptoms and improvement in the ST segment elevation by the end of the procedure.

$\mathrm{Mr} \mathrm{ABH}$ was started on an infusion of intravenous Eptifibatide (glycoprotein Ilb/IIla inhibitor) for 24 hours post $\mathrm{PCl}$. Mr ABH was subsequently discharged with oral Clopidogrel $75 \mathrm{mg}$ and Rivaroxaban $20 \mathrm{mg}$ once daily. His left ventricular ejection fraction was $45 \%$. There was no atrial fibrillation documented during his hospitalization. 


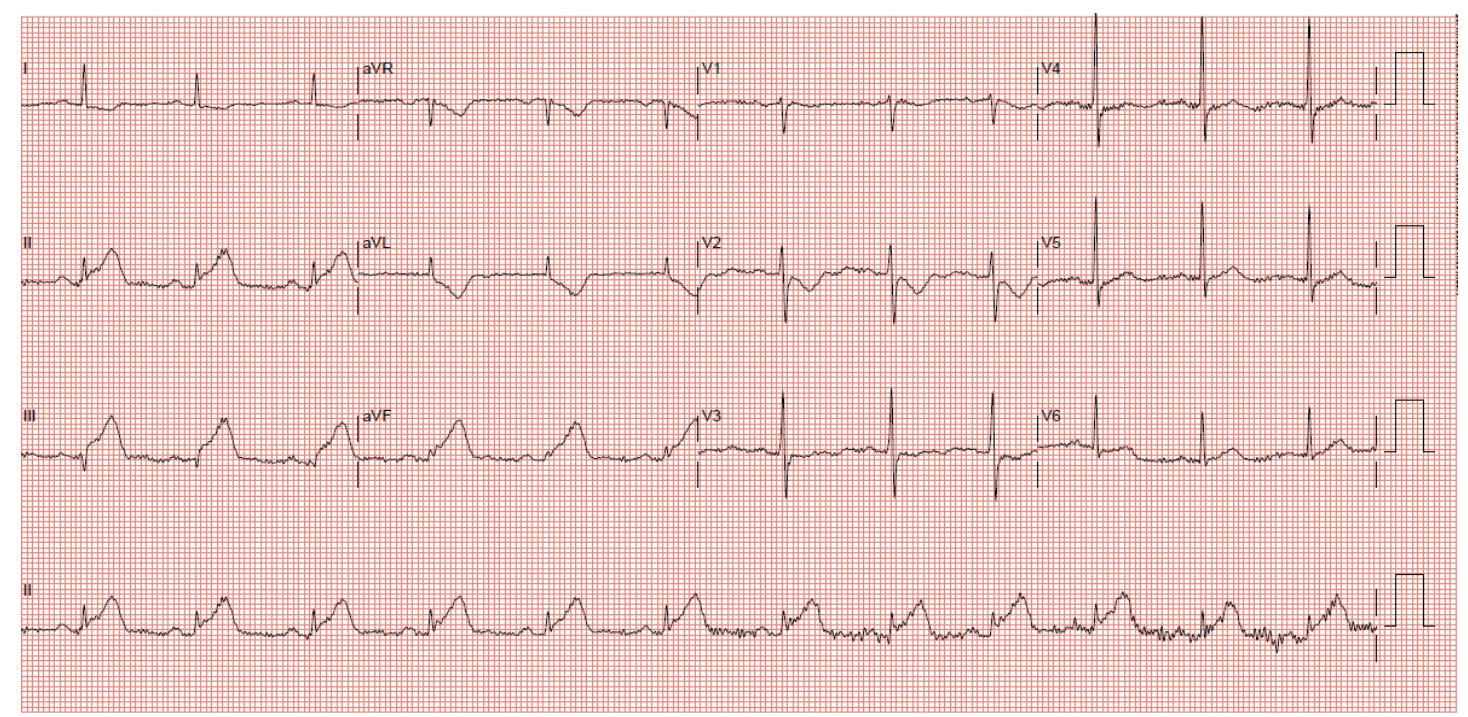

Figure 1: Showing inferior ST segment elevation on ECG.

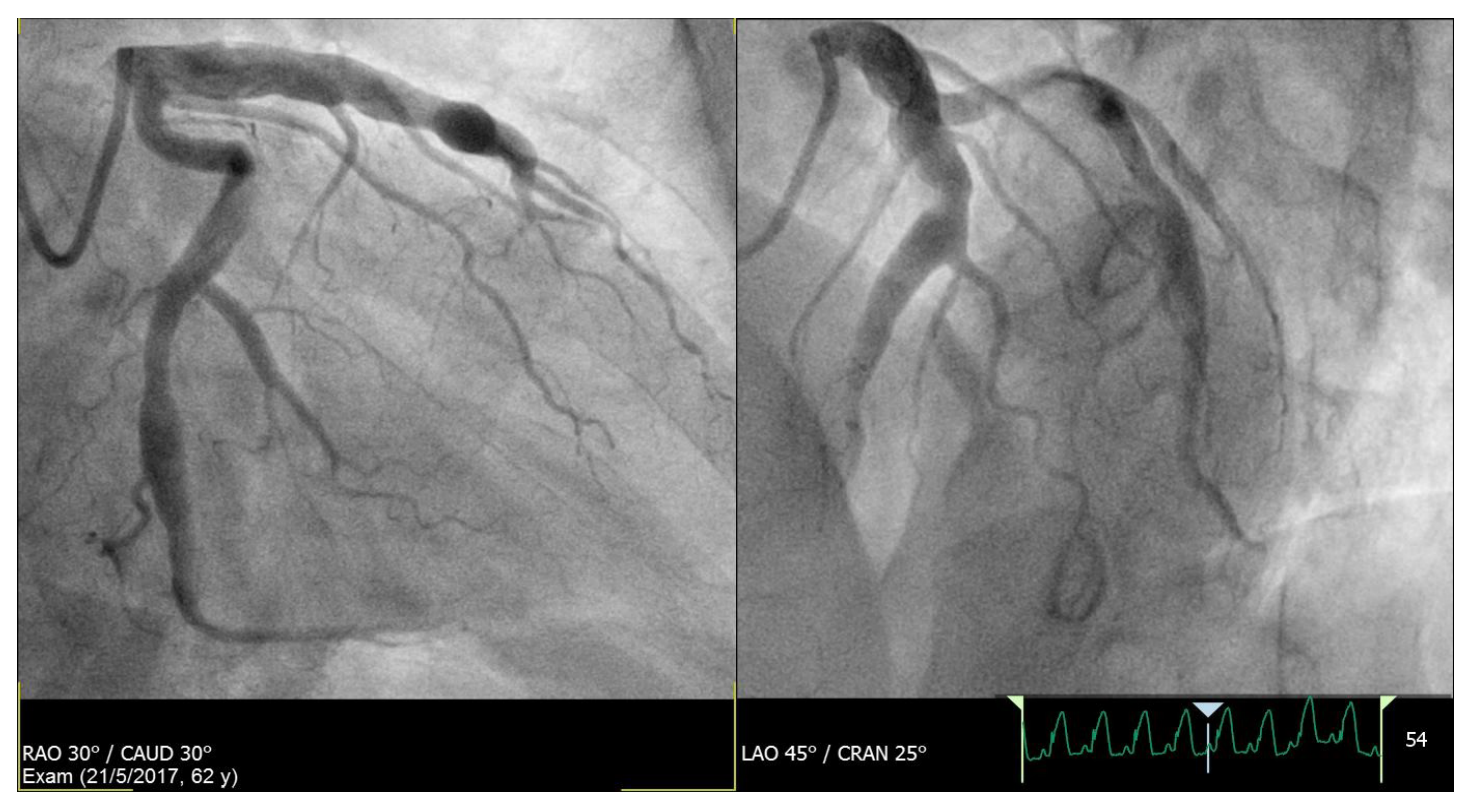

Figure 2: a,b) Showing aneurysmal changes in the left coronary arteries.
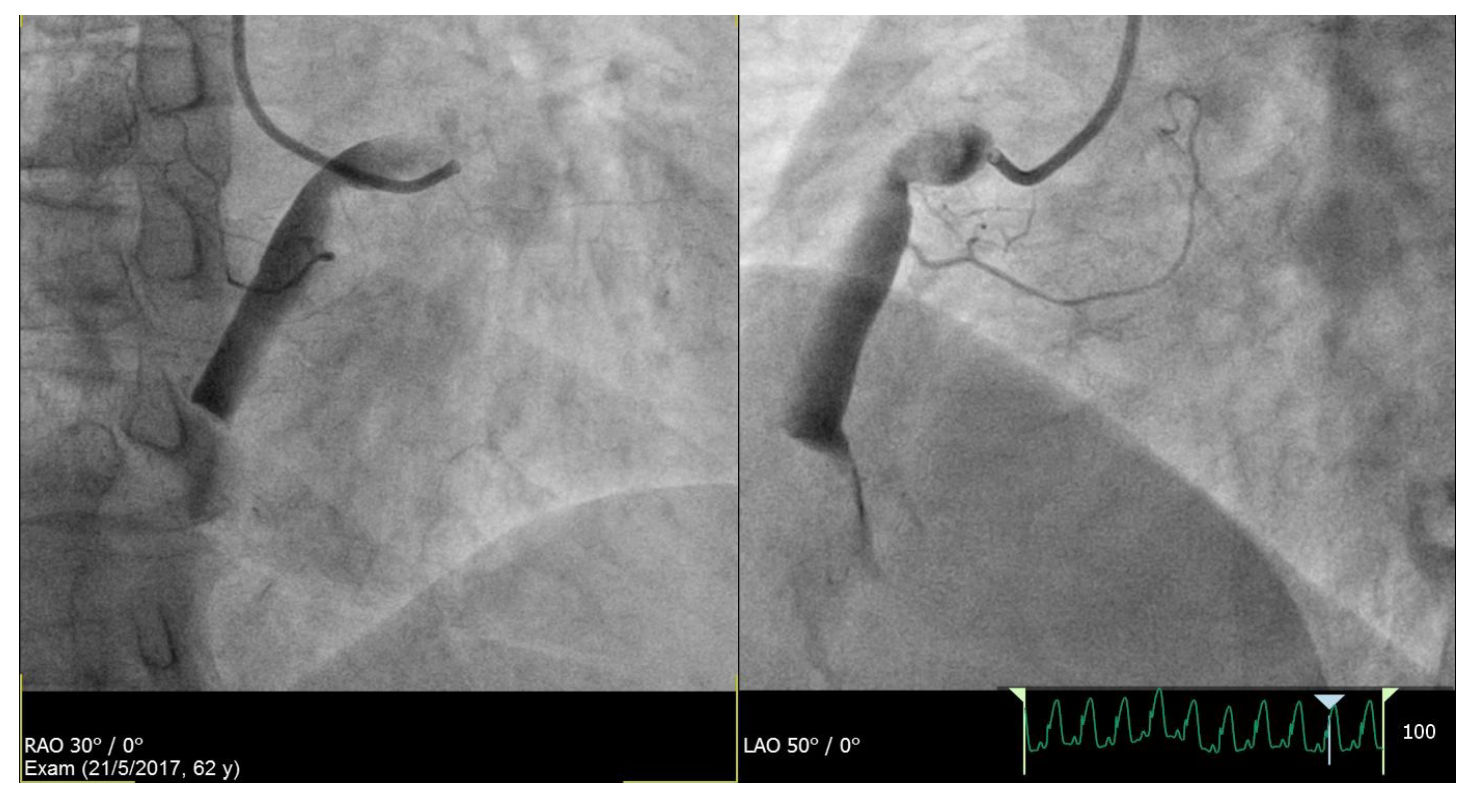

Figure 3: a,b) Showing acute thrombotic occlusion of the mid segment of the giant RCA aneurysm. 


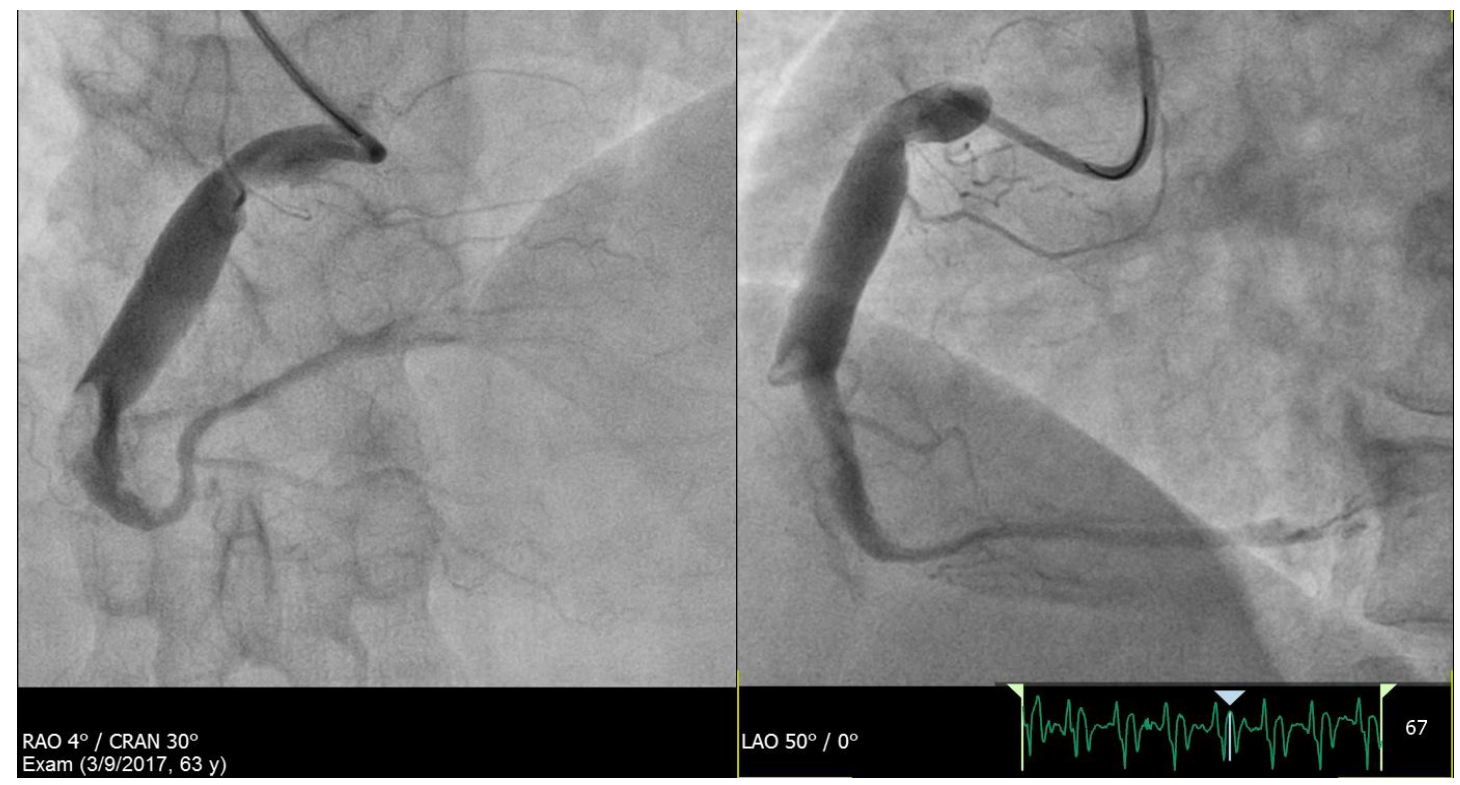

Figure 4: a,b) Showing final result post $\mathrm{PCl}$.

Unfortunately, $\mathrm{Mr} \mathrm{ABH}$ presented again 4 months later with a recurrent inferior STEMI. He was brought to the cardiac catheterization laboratory for emergency $\mathrm{PCl}$. Again, there was a total thrombotic occlusion at the aneurysmal segment of the mid RCA.

Rheolytic thrombectomy was again performed using the Angiojet ${ }^{\mathrm{TM}}$ (Boston Scientific). There was a residual thrombus despite multiple attempts at balloon dilatation and thrombectomy. Further $\mathrm{PCl}$ attempt was not attempted as TIMI3 flow was achieved and the patient had resolution of chest pain symptoms. He was started on an infusion of intravenous Eptifibatide (glycoprotein $\mathrm{Ilb} / \mathrm{Illa}$ inhibitor) for 24 hours post $\mathrm{PCl}$ (Figure $4 \mathrm{a}$ and Figure 4b).

This time, $\mathrm{Mr} \mathrm{ABH}$ was treated with dual anti-platelets (Aspirin $100 \mathrm{mg}$ and Clopidogrel $75 \mathrm{mg}$ once daily) as well as oral warfarin (with a target international normalized ration (INR) of 2-3). His left ventricular ejection fraction remained at $45 \%$ on discharge. He was switched from the triple therapy to just oral Clopidogrel $75 \mathrm{mg}$ and warfarin once daily after 6 months. $\mathrm{Mr} \mathrm{ABH}$ has remained well on follow up in the outpatient clinic for the past 18 months with no recurrence of chest symptoms.

\section{Discussion}

Coronary artery aneurysms are uncommon and are described as a gross dilatation of a coronary artery by more than 1.5 times the diameter of a normal reference segment [1]. The incidence of coronary artery aneurysms are ranges from $0.2 \%-10 \%$. Giant coronary artery aneurysm is defined as such when the diameter exceeds $8 \mathrm{~mm}$ [2-5]. The prevalence of giant coronary artery aneurysms is reported to be around $0.02 \%$ and with a predilection for the right coronary artery [6-8].

Patients with giant coronary artery aneurysms can suffer from complications such as myocardial isch- aemia/infarction or even rupture of the aneurysmal coronary artery. There is limited data to address the management of acute coronary thrombosis in coronary artery aneurysm. Systemic anticoagulation had been proposed by Swanton, et al. [9] to mitigate the risk of coronary artery aneurysm thrombosis. The use of Warfarin and aspirin combination had shown reduction in rates of myocardial infarctions and coronary artery occlusions in a meta-analysis by Su, et al. [10].

Common strategies involve the use of anti-platelet or anti-coagulant therapies although this is lacking in evidence [11]. In this case where the patient initially presented with acute thrombotic occlusion of the giant coronary artery aneurysm, he was treated with a combination of single antiplatelet therapy (Clopidogrel $75 \mathrm{mg}$ once daily) and a novel anti-coagulant Rivaroxaban 20 mg once daily (Xarelto ${ }^{\mathrm{TM}}$, Bayer). Unfortunately, the patient developed a recurrent thrombotic occlusion again 4 months later. Following a repeat emergent $\mathrm{PCl}$, he was treated with a combination of dual anti-platelet therapy consisting of Aspirin, Clopidogrel as well as a vitamin $\mathrm{K}$ antagonist Warfarin. This regime appeared to be more successful. He was changed to single anti-platelet Clopidogrel and Warfarin after 6 months. He had remained well for over 18 months with no recurrence of ischaemic events. There are limited options for therapies directed at the giant coronary artery aneurysm as there are no available coronary stents to match the diameter of the aneurysm. Unfortunately we do not have any large sized covered stents, vascular stents in our cardiac catheterization laboratory facility. The use of covered stents is an alternative in selected cases depending on the size of the aneurysmal segment $[3,12]$. In this case of gross coronary aneurysm (measuring at least $9-10 \mathrm{~mm}$ in diameter), we had no available stents to match the size of the vessel. Best attempts have been made to reduce the thrombus burden as much as possible with the use 
of aspiration thrombectomy devices. The management strategy that will likely have the greatest impact will be the use of combination of anti-thrombotics.

This case demonstrated the failure of the combination of novel anticoagulant with single antiplatelet regime. However, we must bear in mind that the failure of treatment in this case relates only specifically to only one of the few available novel anticoagulants. The optimal anti-thrombotic regime remains unclear due to the limited clinical experience. It is also important to be cognizant of the possibility of other complications such as rupture. Surgical ligation remains a possible treatment option should the patient present with further ischaemic events.

Further studies will be needed to provide more evidence to guide the management of this uncommon and challenging condition.

\section{Acknowledgments}

\section{Conflict of interest}

The authors have no conflicts of interest to declare.

\section{References}

1. PS Swaye, LD Fisher, $P$ Litwin, PA Vignola, MP Judkins, et al. (1983) Aneursymal coronary artery disease. Circulation 67: $134-138$

2. Ozturk S, Yetkin E, Waltenberger J (2018) Molecular and cellular insights into the pathogenesis of coronary artery ectasia. Cardiovasc Pathol 35: 37-47.

3. Abou Sherif S, Ozden Tok O, Taşköylü Ö, Goktekin O, Kilic ID (2017) Coronary artery aneurysms: A review of the epidemiology, pathophysiology, diagnosis and treatment. Front Cardiovasc Med 4: 24.

4. Mata KM, Fernandes CR, Floriano EM, Martins AP, Rossi MA, et al. (2012) Coronary Artery Aneurysms: An Update. In: Lakshmanadoss $U$, Novel strategies in ischemic heart disease. Intech Open, 381-404.

5. Ramos SG, Mata KM, Martins CC, Martins AP, Rossi MA (2008) Giant right coronary artery aneurysm presenting as a paracardiac mass. Cardiovasc Pathol 17: 329-333

6. Li D, Wu Q, Sun L, Song Y, Wang W, et al. (2005) Surgical treatment of giant coronary artery aneurysm. J Thorac Cardiovasc Surg 130: 817-821.

7. Takahashi K, Oharaseki T, Naoe S, Wakayama M, Yokouchi Y (2005) Neutrophilic involvement in the damage to coronary arteries in acute stage of Kawasaki disease. Pediatr Int 47: 305-310.

8. Hartnell GG, Parnell BM, Pridie RB (1985) Coronary artery ectasia: Its prevalence and clinical significance in 4993 patients. Br Heart J 54: 392-395.

9. Swanton RH, Thomas ML, Coltart DJ, Jenkins BS, WebbPeploe MM, et al. (1978) Coronary artery ectasia-a variant of occlusive coronary arteriosclerosis. Br Heart J 40: 393-400.

10. Su D, Wang K, Qin S, Pang Y (2014) Safety and efficacy of warfarin plus aspirin combination therapy for giant coronary artery aneurysm secondary to Kawasaki disease: A metaanalysis. Cardiology 129: 55-64.

11. Ole-Gunnar Anfinsen Lars Aaberge, Odd Geiran, HansJørgen Smith, Svend Aakhus (2004) Coronary artery aneurysms mimicking cardiac tumour. Eur J Echocardiogr 5: $308-312$

12. Cereda AF, Tiberti G, Pera IG, Cantù E, Ferri LA, et al. (2017) A giant coronary artery aneurysm treated using multiple overlapping covered stents. JACC Cardiovascular Interventions 10: E127-E128. 